\title{
Sugar Cane Trash Pyrolysis for Bio-oil Production in a Fluidized Bed Reactor
}

\author{
Wasakron Treedet ${ }^{1}$ and Ratchaphon Suntivarakorn ${ }^{2 *}$ \\ Department of Mechanical Engineering, Faculty of Engineering, Khon Kaen University, Khon Kaen, Thailand \\ ${ }^{1}$ Email: me-kku@hotmail.com, Tel: +66 819745248, Fax: +66 43347879 \\ * Corresponding author, ${ }^{2}$ E-mail: ratchaphon@kku.ac.th, Tel: +66 819891983, Fax: +66 43347879
}

\begin{abstract}
The objective of this work was to study bio-oil production from sugar cane trash by a pyrolysis process in fluidized bed reactor. The experiments were carried out at different temperatures ranging from $460-$ $540{ }^{\circ} \mathrm{C}$ and at different medium gas flow rates between $120-160 \mathrm{cc} . \mathrm{s}^{-1}$. Two different gases, Nitrogen $\left(\mathrm{N}_{2}\right)$ and air, were used as the fluidizing medium in order to study the effect of a different medium on the yield and properties of the bio-oil. The experimental result showed that the maximum bio-oil yields of $46.2 \mathrm{wt} \%$ and 31.95 wt \% were obtained at $500{ }^{\circ} \mathrm{C}$ and $160 \mathrm{cc.s}^{-1}$ for air and Nitrogen medium, respectively. The bio-oil yield obtained when using air as a medium was higher than that when using Nitrogen medium. This was a result of the higher quantity of water content in the air. The properties of bio-oil were determined and the result showed that

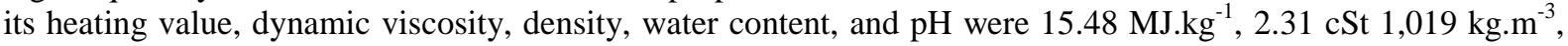
$52 \mathrm{wt} \%$ and 3, respectively. By dehydration of the obtained bio-oil, the heating value, viscosity and density were increased to $19.81 \mathrm{MJ}^{-1} \mathrm{~kg}^{-1}, 57.66 \mathrm{cSt}$ and $1,260 \mathrm{~kg} \cdot \mathrm{m}^{-3}$, respectively. These results show that the bio-oil can be used as a fuel oil for combustion in a boiler or a furnace without any modification. Furthermore, the energy consumption of the pyrolysis process was analyzed.
\end{abstract}

Keywords: Sugar cane trash, Bio-oil, Pyrolysis, Fluidized bed reactor.

\section{Introduction}

Biomass is widely considered as a major potential for renewable energy in the future. Residual biomass and renewable materials can be converted by a pyrolysis process to a combustible liquid usually termed as bio-oil. Bio-oil is renewable and biodegradable and has some advantages in transport, storage, combustion, retrofitting and flexibility in production and marketing. The bio-oil can be used in engines, turbines and furnaces for power generation. The bio-oil obtained from agricultural residuals is a form of renewable energy. In principle, utilizing this energy, in contrast to fossil fuels, does not add carbon dioxide, a greenhouse gas, to the atmospheric environment. Therefore, bio-oil can be recognized as a potential source of renewable energy based on the benefits of both energy recovery and environmental protection. Due to the lower contents of sulfur and nitrogen in agricultural residuals, its energy utilization also creates less environmental pollution than fossil fuel combustion.

Sugar cane trash from agricultural residues is abundant in Thailand which has an annual production of more than 10 million-tons [1]. Traditional methods such as composting and incineration are not suitable to process these organic solid wastes, as they contain small concentrations of $\mathrm{N}_{2}$ for composting and smoke would be released to pollute the environment during incineration. Therefore, a practical method would be to pyrolyze cane trash to provide bio-oil. Currently, the potential of pyrolysis conditions for bio-oil production have been investigated. Asadullah et al. [2] has studied the pyrolysis of jute stick for bio-oil production in a continuous feeding fluidized bed reactor. The experimental results showed that the maximum yield of bio-oil was $66.7 \mathrm{wt} \%$ at $500{ }^{\circ} \mathrm{C}$. Ji-lu et al. [3] pyrolyzed cotton stalk in a fluidized bed using nitrogen as the carrier gas to fluidize the cotton stalk with sand. From the experiment, the yield of bio-oil first increased and then decreased as a function of the combustion temperature and the maximum yield of bio-oil was $55 \mathrm{wt} \%$ obtained at $510{ }^{\circ} \mathrm{C}$. 
Furthermore, bio-oil production from many kinds of biomass, such as China Fir, Manchurian ash, Padauk wood, rice straw and rice husk has been performed in a fluidized bed reactor by fast pyrolysis [4-5]. The experimental results showed that the yield of bio-oil varied with combustion temperature, heating rate and volumetric flow-rate of nitrogen gas. Besides, using a fluidized bed reactor for bio-oil production, a fixed bed reactor and an induction-heating reactor have also been investigated [6-8]. From the experiment, it was found that the temperatures, nitrogen flow rates, heating rates and particle sizes play the roles of important parameters for the yield of bio-oil production.

However, at present, there has not been comprehensive research about the bio-oil production from sugar cane trash. The fast pyrolysis of cane trash in a fluidized bed reactor under different conditions was performed in order to know the suitable conditions of the parameters to produce the maximum bio-oil production and to determine the properties of bio-oil obtained. The effects of combustion temperature, flow rate of carrier gas and type of fluidizing medium were investigated. Furthermore, the energy consumption for bio-oil production was also analyzed.

\section{Experimental material, device, method and procedure}

\subsection{Experimental material}

The experimental materials include cane trash, sand, air and nitrogen $\left(\mathrm{N}_{2}\right)$. The physical properties of the cane trash and sand, such as density, porosity and diameter, are listed in Table 1 . The proximate analysis and ultimate analysis of the cane trash are listed in Table 2 and Table 3, respectively. The sugar cane trash had dimensions of 1 × $3 \mathrm{~mm}$ and $5.94 \mathrm{wt} \%$ of moisture content in feedstock. Sand was used as the thermal carrier to transfer heat quickly from the hot $\mathrm{N}_{2}$ (or air) to the cane trash. $\mathrm{N}_{2}$ (or air) was used as the carrier gas to fluidize the cane trash with sand in the fluidized bed reactor.

Table 1. Physical properties of experimental material.

\begin{tabular}{lcc}
\hline \multicolumn{1}{c}{ Physical properties } & Cane trash & Sand \\
\hline Density $\left(\mathrm{kg} . \mathrm{m}^{-3}\right)$ & 347.61 & $3,793.27$ \\
Porosity (\%) & 50.72 & 41.31 \\
Diameter (mm) & $1-3$ & 0.332 \\
\hline
\end{tabular}

Table 2. Proximate analysis of sugar cane trash.

\begin{tabular}{lc}
\multicolumn{1}{c}{ Properties } & Value \\
\hline Fixed carbon (wt\%) & 21.26 \\
Volatile matter (wt\%) & 70.86 \\
Moisture content (wt\%) & 4.55 \\
Ash (wt\%) & 3.33 \\
Heating Value (MJ.kg ${ }^{-1}$ ) & 18.3 \\
\hline
\end{tabular}

Table 3. Ultimate analysis of sugar cane trash.

\begin{tabular}{lcc}
\hline & Properties & Value (wt\%) \\
\hline $\mathrm{C}$ & 51.21 \\
$\mathrm{H}$ & 5.16 \\
$\mathrm{~N}$ & 1.93 \\
$\mathrm{O}$ & 40.33 \\
$\mathrm{~S}^{*}$ & 1.37 \\
\hline
\end{tabular}

Sulfur calculated by difference. 


\subsection{Experimental set-up}

As shown in Fig. 1, the experimental device consisted mainly of a hopper, two cyclones and a condenser as well as seven thermocouples. The hopper was used to contain feedstock such as cane trash. The two screw feeders had the same configuration and size; the first one was used to control the feeding rate and the second one operated at a relatively high speed to prevent jamming the feeding system. The fluidized bed reactor operated at atmospheric pressure using $\mathrm{N}_{2}$ (or air) as the fluidizing medium gas. The reactor had a height of 1.54 meter and a diameter of $10 \mathrm{~cm}$ in which the cane trash was rapidly heated for pyrolysis. The $6,000 \mathrm{~W}$ electric heater was able to pre-heat the $\mathrm{N}_{2}$ (or air) to a temperature range of $500{ }^{\circ} \mathrm{C}-620{ }^{\circ} \mathrm{C}$ before entering the fluidized bed reactor. The two cyclones were used to separate solid particles, such as charcoal and ash, from the hot gas. The condenser was equipped with copper pipes and a cooling tank. The condenser was able to quickly cool the cleaned hot gas into a liquid. Thermocouples were used to monitor and control the pyrolysis system. The locations of all measurement sensors, including the seven thermocouples are shown in Fig. 1. The specification of the thermocouples is K Type, made from an alloy of chromel - alumel, measurement range from $-200{ }^{\circ} \mathrm{C}$ to $1,372{ }^{\circ} \mathrm{C}$ with measurement accuracy of the thermocouples of $\pm 2{ }^{\circ} \mathrm{C}$. The Fuzzy+PID logic was used in the temperature control system.

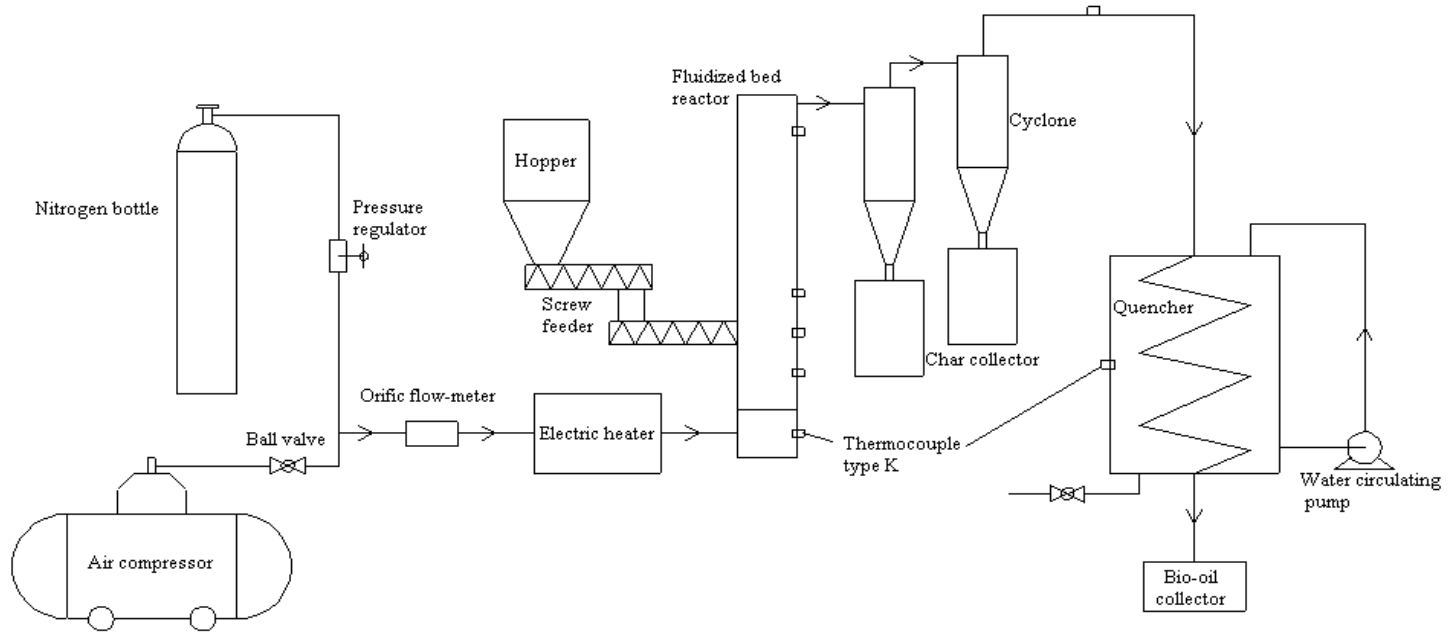

Fig. 1. The experimental set-up.

\subsection{Experimental method}

The experiment device was originally set up at Khon Kaen University in 2010 and presently scaled up to a cane trash feeding rates of $10 \mathrm{~kg} \cdot \mathrm{h}^{-1}$. The cane trash powder had dimensions between $1-3 \mathrm{~mm}$ and was fed continuously into the reactor. The pyrolysis experiments using

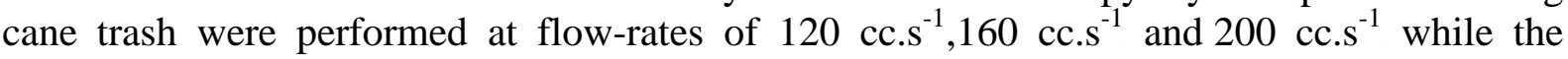
temperature was ranged from $460{ }^{\circ} \mathrm{C}-540{ }^{\circ} \mathrm{C}$ under $\mathrm{N}_{2}$ atmosphere., The pyrolysis experiments using cane trash were also performed in a different medium gas at a flow-rate of

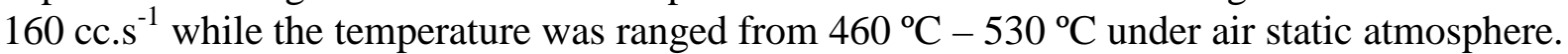
The yield of the bio-oil was heavily impacted by the rate of cooling in condenser. The cooling must be quick; otherwise, some condensable gas will be converted into non-condensable gas (NCG) [5]. Thus, in our experiment, the heat exchanger was operated in cool water and ice with a condensation temperature of $-4^{\circ} \mathrm{C}$.

Besides bio-oil, two byproducts, namely charcoal and NCG, can also be obtained when cane trash is pyrolyzed. The yield of the bio-oil can be determined from the condensed liquid and the feedstock used. The yield of the charcoal can be calculated by dividing the ash contents in 
the feedstock with that in the charcoal. The yield of NCG can be determined from the fact that the sum of the three product yields should equal $100 \%$.

\subsection{Experimental procedure}

1. Turn on the electric heater and turn on the $1^{\text {st }}$ motor of the feeder to prevent jamming the feeding system.

2. Transport $\mathrm{N}_{2}$ into the pyrolysis system with a flow rate of 120 cc.s $^{-1}$.

3 . When the temperature of the fluidized bed reactor reaches the expected temperature, turn on the $2^{\text {nd }}$ motor of the feeder to transport1 $\mathrm{kg}$ of cane trash into the fluidized bed reactor. The expected temperature was varied from $460-540^{\circ} \mathrm{C}$.

4. After 45 minutes, stop transporting cane trash into the fluidized bed reactor.

5. Turn off the electric heater and the water circulating pump.

6 . Then, stop transporting $\mathrm{N}_{2}$ into the pyrolysis system.

7. Collect the bio-oil and charcoal for the experiment.

8. Perform the experimental steps (1)-(7) again by varying the flow rate of $\mathrm{N}_{2}$ from 120 Cc.s ${ }^{-1}$ to 160 cc.s ${ }^{-1}$ and 200 cc.s ${ }^{-1}$, respectively.

9. Perform the experimental steps (1)-(8) again by changing the fluidizing medium from $\mathrm{N}_{2}$ to air.

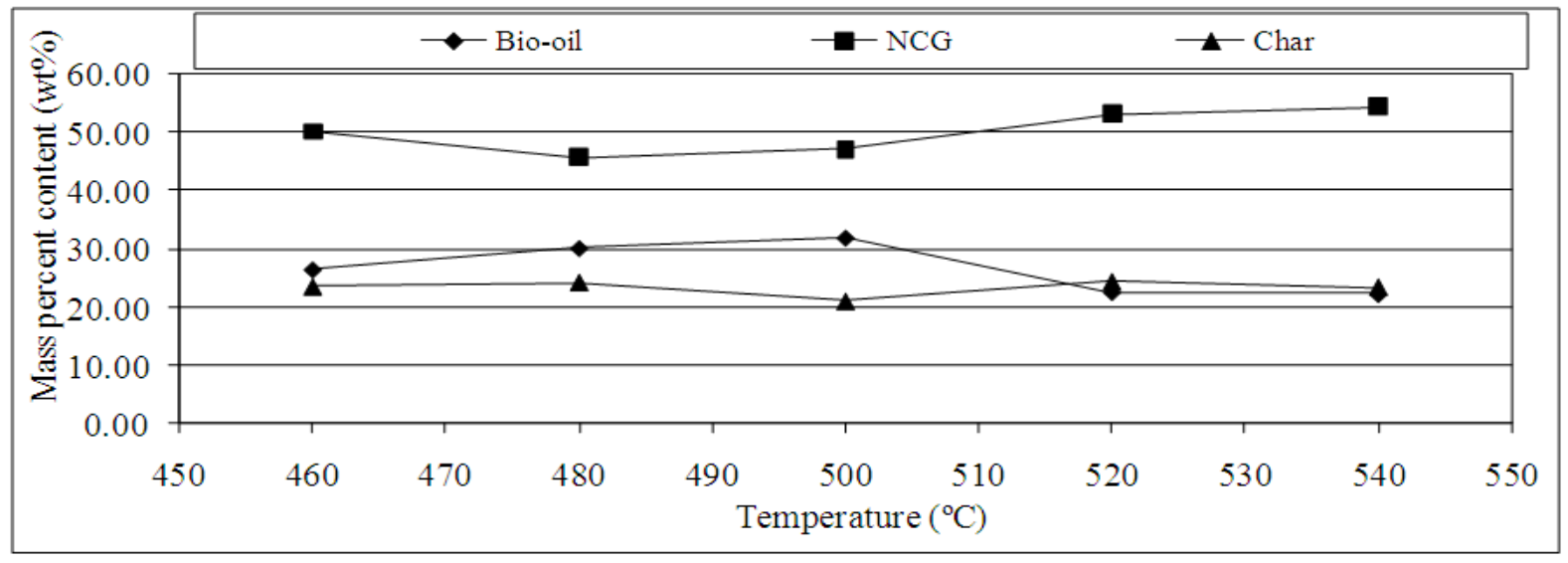

Fig. 2. Relationship between pyrolysis temperature and product yields for $\mathrm{N}_{2}$ medium at flow-rate of $160 \mathrm{cc} . \mathrm{s}^{-1}$ and temperature between $460^{\circ} \mathrm{C}-540^{\circ} \mathrm{C}$.

\section{Results and discussions}

\subsection{Effect of temperature on the product distribution}

Our preliminary experiments show that a $\mathrm{N}_{2}$ temperature below $460{ }^{\circ} \mathrm{C}$ is not sufficient for pyrolysis, as some cane trash was found in the charcoal and ash. In contrast, $\mathrm{N}_{2}$ temperatures above $540{ }^{\circ} \mathrm{C}$ are too high, as the yield of bio-oil is quickly reduced. Therefore, for these particular materials, the optimum temperature for pyrolysis seems to be within the range of $460{ }^{\circ} \mathrm{C}-540{ }^{\circ} \mathrm{C}$. The relationship between the yields of the three products and the pyrolysis temperature at 160 cc.s $\mathrm{s}^{-1}$ of $\mathrm{N}_{2}$ volumetric flow rate is shown in Fig. 2.

From Fig. 2, it can be found that: (1) bio-oil yields first increase and then decrease with an increasing in $\mathrm{N}_{2}$ temperature and the highest yield for cane trash is $31.95 \mathrm{wt} \%$ at $500{ }^{\circ} \mathrm{C}$, (2) NCG yields always increase with an increase in $\mathrm{N}_{2}$ temperature and (3) charcoal yields always decrease with an increase in $\mathrm{N}_{2}$ temperature. The influence of pyrolysis temperature is the same as the results of Z. Ji-lu et al. [3], S. Wang et al. [4] and Z. Ji-lu. [5], but the maximum yield of the bio-oil in their experiments is not equal to our experimental results. 
The influence of pyrolysis temperature and the yield of the three products in air medium are shown in Fig. 3. It can be found that: the highest bio-oil yield of $46.2 \mathrm{wt} \%$ was obtained at an air temperature of $500{ }^{\circ} \mathrm{C}$ and a volumetric air flow rate of $160 \mathrm{cc} . \mathrm{s}^{-1}$. The function of the air temperature to the product yields is similar to the function of $\mathrm{N}_{2}$ temperature. The result showed that the yield of bio-oil from air medium was higher than the yield of bio-oil from $\mathrm{N}_{2}$ medium. This is caused by the higher water content in the air.

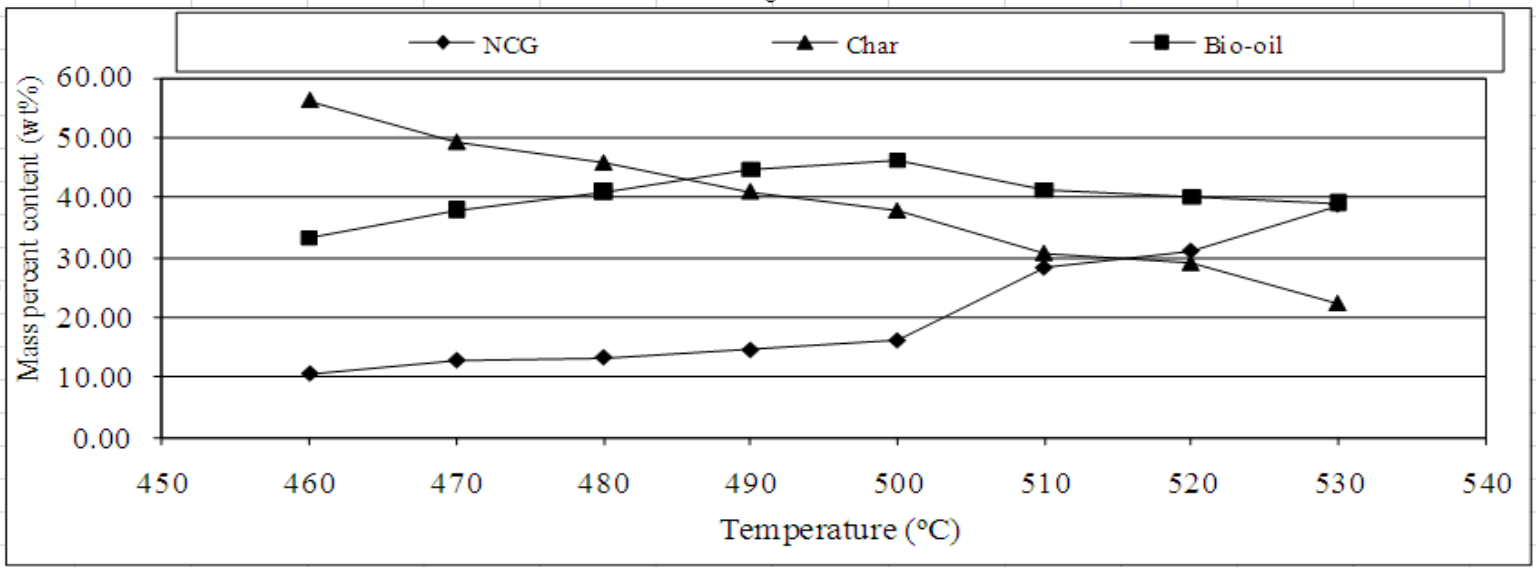

Fig. 3. Relationship between pyrolysis temperature and product yields for air medium at flow-rate of $160 \mathrm{cc} . \mathrm{s}^{-1}$ and temperature between $460^{\circ} \mathrm{C}-530^{\circ} \mathrm{C}$.

\subsection{Effect of flow rate on product distribution.}

It is known that sweeping the reactor with $\mathrm{N}_{2}$ could increase the oil yield because sweeping the environment shortens the residence time of volatiles and reduces their chances of being involved in char and radical forming secondary reactions [6]. Fig. 4 shows the effect of the flow rate of $\mathrm{N}_{2}$ on the production yield from cane trash pyrolysis. at a temperature of $500{ }^{\circ} \mathrm{C}$. The relationship between the $\mathrm{N}_{2}$ flow-rate and the production yield shows that: (1) bio-oil yields first increase and then decrease with an increase in flow-rate and the highest yield for

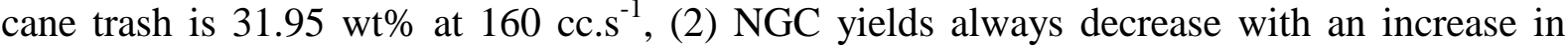
flow-rate and (3) charcoal yields always increase with the increase in flow-rate. This influence of the $\mathrm{N}_{2}$ flow-rate is the same as the experimental result of $\mathrm{M}$. F. Parihar et al. [6].

The decrease in bio-oil yields when flow-rate is increased may be due to the very short residence time of the vapors in the condenser and vapors unable to condense due to higher percentage of NGC. Furthermore, the increase in char yields when the flow-rate is increased may be due to un-burned cane trash in the reactor.

\subsection{Effect of fluidizing medium gas on the products distribution.}

Pyrolysis is a thermal decomposition occurring in the absence or less than $30 \%$ theory of air [9]. Bio-oil has a water content as high as 15 - $45 \mathrm{wt} \%$ derived from the original moisture in the feedstock and produced by the dehydration of air during the pyrolysis reaction and during storage. The presence of water lowers the heating value and the flame temperature, but on the other hand, water reduces the viscosity and enhances the fluidity, which is good for the atomization and combustion of bio-oil in the engine. Furthermore, the presence of oxygen creates the primary issue for the differences between bio-oils and hydrocarbon fuels. The high oxygen content leads to an energy density lower than that of conventional fuel by $50 \%$ and also an immiscibility with hydrocarbon fuels. In addition, the strong acidity of bio-oils makes 
them extremely unstable. Therefore, the use of air as the fluidizing medium has an effect on the yield and properties of the bio-oil.

From the bio-oil production experiment using a different fluidizing medium, either air or $\mathrm{N}_{2}$, the result showed that using air medium can produce a higher yield of bio-oil than that with $\mathrm{N}_{2}$ medium, about $9.25 \% \mathrm{wt}$ at pyrolysis temperature of $500{ }^{\circ} \mathrm{C}$ and a flow rate of $160 \mathrm{cc.s}{ }^{-1}$. In addition, the bio-oil production from air medium had a high moisture content of $81.11 \% \mathrm{wt}$ while the bio-oil production from $\mathrm{N}_{2}$ medium had a moisture content of $52.14 \%$ wt. This result revealed that the air medium has a higher water content which has the advantage of reducing the viscosity of the bio-oil, but also the disadvantage of causing a lower heating value.

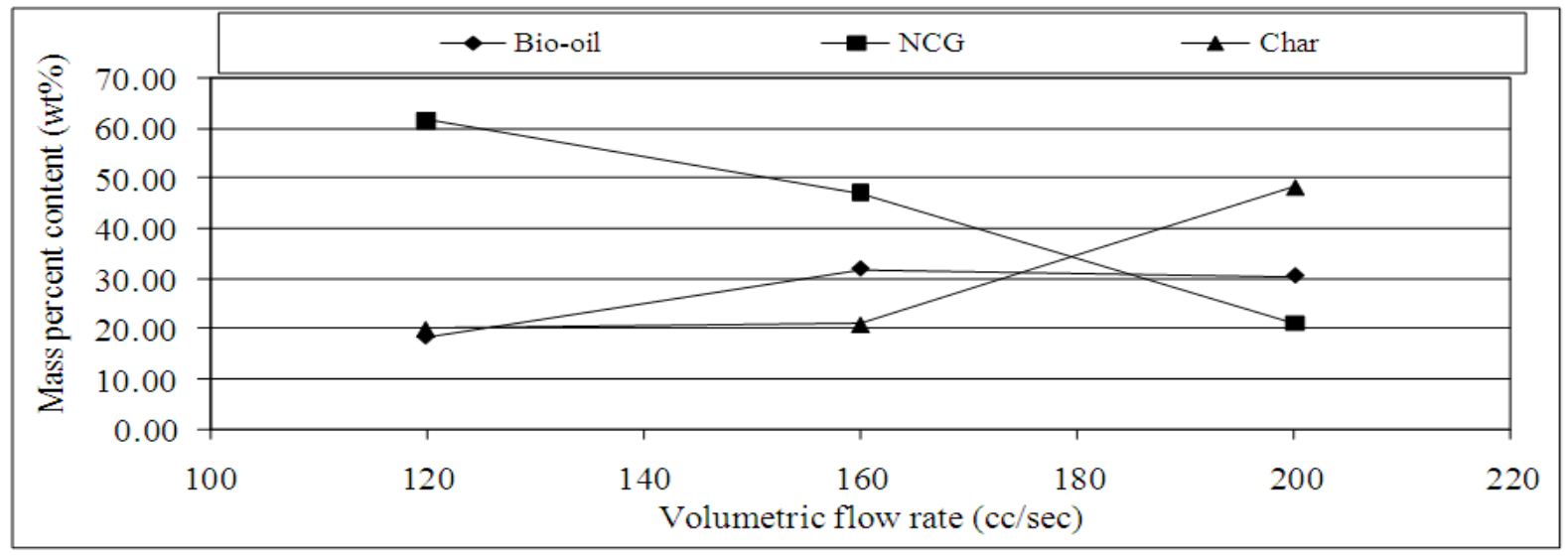

Fig. 4. Effect of flow rate on product yields from cane trash pyrolysis at temperature of $500{ }^{\circ} \mathrm{C}$ and varying flow-rate of $120 \mathrm{cc} . \mathrm{s}^{-1}, 160 \mathrm{cc} . \mathrm{s}^{-1}$ and $200 \mathrm{cc} . \mathrm{s}^{-1}$

\subsection{Properties of the bio-oil.}

The main properties of the bio-oil from cane trash are shown in Table 4. The low heating value (LHV) of bio-oil production from $\mathrm{N}_{2}$ medium is higher than that from air medium because the air has a higher quantity of water content. Furthermore, the density, viscosity and $\mathrm{pH}$ of bio-oil production from $\mathrm{N}_{2}$ medium and air medium are very comparable. To increase the heating value of the bio-oil, the water content in the bio-oil was dehydrated. The properties of the bio-oil after dehydration are shown in Table 5. The heating value, density and viscosity were increased while the $\mathrm{pH}$ was decreased for both $\mathrm{N}_{2}$ and air medium.

Table 4. Main properties of bio-oil from cane trash.

\begin{tabular}{lcc}
\hline \multicolumn{1}{c}{ Physical properties } & Nitrogen medium & Air medium \\
\hline Heating value $\left({\left.\mathrm{MJ} . \mathrm{kg}^{-1}\right)}^{-1}\right)$ & 15.48 & 1.36 \\
Density $\left(\mathrm{kg} \cdot \mathrm{m}^{-3}\right)$ & 1019.20 & 1010.12 \\
Water content $(\mathrm{wt} \%)$ & 52.14 & 81.11 \\
Viscosity $(\mathrm{cSt})$ at $40^{\circ} \mathrm{C}$ & 2.31 & Similar to water \\
$\mathrm{pH}$ & 3 & 3 \\
\hline
\end{tabular}

Table 5. Main properties of bio-oil after dehydration.

\begin{tabular}{lcc}
\multicolumn{1}{c}{ Physical properties } & Nitrogen medium & Air medium \\
\hline Heating value $\left({\left.\mathrm{MJ} . \mathrm{kg}^{-1}\right)}^{-1}\right.$ & 19.81 & 16.55 \\
Density $\left(\mathrm{kg} . \mathrm{m}^{-3}\right)$ & 1260 & 1230 \\
Viscosity $(\mathrm{cSt})$ at $40^{\circ} \mathrm{C}$ & 57.66 & - \\
$\mathrm{pH}$ & 2 & 2 \\
\hline
\end{tabular}




\subsection{The energy consumption of the pyrolysis process.}

The energy consumption of the bio-oil production using both $\mathrm{N}_{2}$ and air as a medium was analyzed, and the results are shown in Table 6. The energy consumption was divided into two time periods which are during the pre-heating process and during the combustion process. During the pre-heating process, the reactor and fluidizing medium were heated by using a 6 $\mathrm{kW}$ heater and the fluidizing medium was transported by using an $15 \mathrm{hp}$ air compressor. During the combustion process, the additional energy consumption was obtained from the use of two $120 \mathrm{~W}$ screw feeders for transporting the cane trash. To determine the energy consumption, the electric power was measured by watt meter and the working time of the process was recorded. The electric energy consumption $\left(\mathrm{MJ}_{\mathrm{kg}}{ }^{-1}\right.$ sugarcane trash $)$ was calculated by multiplication of the electric power $(\mathrm{kW})$ by the number of working hours (h). From the calculation, the energy consumption of the bio-oil production was $131.14 \mathrm{MJ} . \mathrm{kg}^{-1}$ sugarcane trash

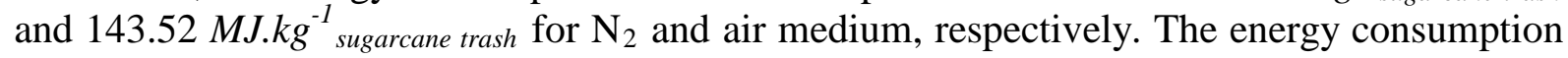
when using $\mathrm{N}_{2}$ medium was less than that when using air medium because the air compressor was not used when using $\mathrm{N}_{2}$ as a medium. It was noted that the total energy consumption of

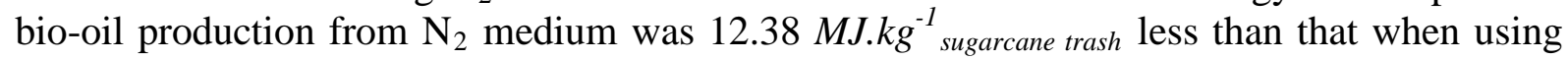
air medium.

Table 6. The energy consumption of the pyrolysis process.

\begin{tabular}{lcc}
\hline \multicolumn{1}{c}{ Energy consumption (MJ.kg-1 ${ }^{-1}$ sugarcane trash) } & $\mathrm{N}_{2}$ medium & Air medium \\
\hline Electric energy from heater during pre-heating process & 64.15 & 64.15 \\
Electric energy from feeder during pre-heating process & 0.97 & 0.97 \\
Electric energy from air compressor during pre-heating process & 55.58 & 55.58 \\
Electric energy from heater during combustion process & 10.15 & 10.15 \\
Electric energy from feeder during combustion process & 0.29 & 0.29 \\
Electric energy from air compressor during combustion process & - & 12.38 \\
Total energy & 131.14 & 143.52 \\
\hline
\end{tabular}

\section{Conclusion}

Bio-oil production from sugar cane trash by a pyrolysis process was conducted in a fluidized bed reactor. The effects of the pyrolysis temperature, flow rate, different fluidizing medium on the yield of bio-oil production were investigated. The properties of the bio-oil and the energy consumption were also studied. The experiments were performed by varying the temperature from $460{ }^{\circ} \mathrm{C}-540{ }^{\circ} \mathrm{C}$ and at flow rates of $120 \mathrm{cc} . \mathrm{s}^{-1}, 160 \mathrm{cc} . \mathrm{s}^{-1}$ and $200 \mathrm{cc} . \mathrm{s}^{-1}$ under air and $\mathrm{N}_{2}$ atmosphere. From the experiment, sugar cane trash can be pyrolyzed into bio-oil. The experimental result showed that the maximum yields of bio-oil were $46.2 \mathrm{wt} \%$

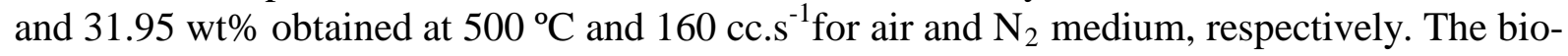
oil yield obtained from using air as a medium was higher than that when using $\mathrm{N}_{2}$ as a medium because of the presence of water content in the air. The result also revealed that the yield of bio-oil varied with the combustion temperature and volumetric flow-rate of the fluidizing medium.

The properties of the obtained bio-oil were determined. It was found that the heating value of bio-oil using $\mathrm{N}_{2}$ medium was higher than that using air medium because air had a higher water content. Furthermore, the density and $\mathrm{pH}$ of the bio-oil production from both $\mathrm{N}_{2}$ and air medium are very comparable. The heating value, viscosity and density of the bio-oil obtained from both $\mathrm{N}_{2}$ and air medium, were increased by dehydration. The energy consumption of

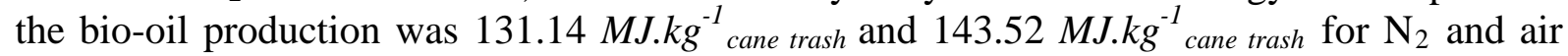
medium, respectively. This was indicated that the energy consumption for bio-oil production 
was more than the energy obtained from the bio-oil. Considering the equipment that consumed the energy, it was found that the electric heater and air compressor consumed the most energy with 83.43 - 91.12\% of the total energy consumption. However, the energy consumption can be reduced by using 2 hp of high pressure blower instead of the $15 \mathrm{hp}$ of air compressor and adding heat recovery system to heat the medium gas before entering to the reactor. According to the energy saving measure, the energy cost will be lower and worthwhile for investment. From the above results, the obtained bio-oil can be used as a fuel oil for combustion in a boiler or a furnace without any modification.

\section{Acknowledgement}

The authors acknowledge the grant from Energy Management and Conservation Office (EMCO) and Engineering Faculty Research Fund to financially support the project reported in this paper. The authors are also grateful to acknowledge the Department of Mechanical Engineering, Faculty of Engineering, Khon Kaen University for supporting the tools and the equipment used in this research.

\section{References}

[1] NEPO (National Energy Policy Office) Journal Volume 50 [online] 2000 [cited 2009 Dec. 7]. Available from : http://www.eppo.go.th/vrs/VRS50-03- FutureFuel.html

[2] M. Asadullah, M.A. Rahman, M.M. Ali, M.A. Motin, M.B. Sultan, M.R. Alam and M.S. Rahman, Jute stick pyrolysis for bio-oil production in fluidized bed reactor, Bioresource Technology 99, 2008, pp. 44-50.

[3] Z. Ji-lu, Y. Wei-ming and W. Na-na, Bio-oil production from cotton stalk, Energy Conversion and Management 49, 2008, pp.1724-1730.

[4] S. Wang, M. Fang, C. Yu, Z. Luo and K. Cen, Flash Pyrolysis of biomass particles in fluidized bed for bio-oil production, China Particuology 3 (1-2), 2005, pp.136 - 140.

[5] Z. Ji-lu, Bio-oil from fast pyrolysis of rice husk: Yields and related properties and improvement of the pyrolysis system, Journal of Analytical and Applied Pyrolysis 80, 2007, pp.30 - 35.

[6] M.F. Parihar, M. Kamil, H.B. Goyal, A.K. Gupta and A.K. Bhatnagar, An experimental study on pyrolysis of biomass, Trans IChemE Part B 85, 2007, pp.458-465.

[7] M. Asadullah, M.A. Rahman, M.M. Ali, M.S. Rahman, M.A. Motin, M.B. Sultan and M.R. Alam, Production of bio-oil from fixed bed pyrolysis of bagasse, Fuel 86, 2007, pp. 2514-2520.

[8] S. Sensoz, D. Angin, Pyrolysis of safflower (Charthamus tinctorius L.) seed press cake in a fixed-bed reactor: Part 2. Structural characterization of pyrolysis bio-oils, Bioresource Technology 99, 2008, pp.5498 - 5504.

[9] A.V. Bridgwater, Biomass fast pyrolysis, Thermal Science 8(2), 2004, pp.21-49. 